\title{
The Evolution of Endurance Running and the Tyranny of Ethnography: A Reply to Pickering and Bunn (2007)
}

\section{Citation}

Lieberman, Daniel E., Dennis M. Bramble, David A. Raichlen, and John J. Shea. 2007. The evolution of endurance running and the tyranny of ethnography: A reply to Pickering and Bunn (2007). Journal of Human Evolution 53(4): 439-442.

\section{Published Version}

doi:10.1016/j.jhevol.2007.07.002

\section{Permanent link}

http://nrs.harvard.edu/urn-3:HUL.InstRepos:3743587

\section{Terms of Use}

This article was downloaded from Harvard University's DASH repository, and is made available under the terms and conditions applicable to Other Posted Material, as set forth at http:// nrs.harvard.edu/urn-3:HUL.InstRepos:dash.current.terms-of-use\#LAA

\section{Share Your Story}

The Harvard community has made this article openly available.

Please share how this access benefits you. Submit a story.

\section{Accessibility}




\title{
The evolution of endurance running and the tyranny of ethnography: A reply to Pickering and Bunn (2007)
}

\author{
Daniel E. Lieberman ${ }^{\mathrm{a}, \mathrm{b}, *}$, Dennis M. Bramble ${ }^{\mathrm{c}}$, David A. Raichlen ${ }^{\mathrm{d}}$, John J. Shea ${ }^{\mathrm{e}}$ \\ ${ }^{a}$ Department of Anthropology, Harvard University, 11 Divinity Avenue, Cambridge, MA 02138, USA \\ ${ }^{\mathrm{b}}$ Department of Organismic \& Evolutionary Biology, Harvard University, 11 Divinity Avenue, Cambridge, MA 02138, USA \\ ${ }^{\mathrm{c}}$ Department of Biology, University of Utah, Salt Lake City, UT 84112, USA \\ ${ }^{\mathrm{d}}$ Department of Anthropology, University of Arizona, 1009 E. South Campus Drive, Tucson, AZ 85721, USA \\ ${ }^{\mathrm{e}}$ Department of Anthropology, Stony Brook University, Stony Brook, NY 11794-4364, USA
}

Received 29 January 2007; accepted 1 July 2007

\section{Introduction}

Endurance running (ER) poses a conundrum for paleoanthropologists. As summarized in Bramble and Lieberman (2004), human ER capabilities, which are unique among primates, either match or exceed those of mammals adapted for running (cursors), including dogs and equids. Because many of the biomechanical and physiological challenges of human ER are so different from those of walking, we can conclude that human ER capabilities did not arise merely as a by-product of selection for walking. Instead, the available evidence suggests that an array of features that improve ER performance were selected in the genus Homo, and they were probably present to some extent by the appearance of Homo erectus at approximately 1.9 Ma. Yet, ER is no longer necessary for human survival, even among extant foragers such as the Hadza or the Bushmen. Thus, a puzzle that paleoanthropologists must solve is identifying what past behaviors-behaviors no longer common among living foragers-favored the evolution of ER.

Pickering and Bunn's (2007) criticisms of the ER hypothesis center on two issues: first, that early Homo lacked the tracking abilities necessary for successful pursuit hunts, and second, that recent ethnographic evidence suggests that modern hunter-

\footnotetext{
* Corresponding author. Department of Anthropology, Harvard University, 11 Divinity Avenue, Cambridge, MA 02138, USA.

E-mail addresses: danlieb@fas.harvard.edu (D.E. Lieberman), Bramble@ bioscience.utah.edu (D.M. Bramble), raichlen@email.arizona.edu (D.A. Raichlen), John.Shea@sunysb.edu (J.J. Shea).
}

gatherers rarely use ER to either hunt or scavenge. These arguments are based on a presumptive link between modernhuman-like cognition and tracking abilities, as well as the notion that the modern ethnographic record provides an adequate reflection of past behaviors. Both of these assumptions are flawed. Although tracking is complex, there is little evidence to suggest that early hominids lacked the tracking abilities of much less encephalized carnivores. Additionally, as noted by Marlowe (2005), comparatively recent inventions, such as the bow and arrow, the spear thrower, nets, and even the spear point, fundamentally altered how humans hunt and scavenge. A strict reliance on the recent ethnographic record, what Wobst (1978) termed the "tyranny of ethnography," is a fundamentally problematic way of testing hypotheses of past hunting behavior. Even so, a review of the ethnographic evidence reveals errors in Pickering and Bunn's contentions.

\section{Tracking abilities}

One of Pickering and Bunn's major concerns with the ER hypothesis is that persistence hunting $(\mathrm{PH})$ in most relatively open African habitats requires a combination of tracking and ER. They consider tracking to have been too cognitively complex for early Homo. There are several problems with this argument. The first is that there is no evidence to support it. Tracking is indeed a complex task, and it requires years of practice and experience (Liebenberg, 1990). Yet, various forms of tracking are practiced by many mammals much less encephalized than any 
hominid using a combination of olfactory, auditory, and visual cues. Human olfactory tracking abilities are also underrated (Porter et al., 2007). It is difficult to imagine that a H. erectus hunter with significantly more encephalization than any carnivore could not also have performed rudimentary tracking. Moreover, these hominids could make sophisticated tools involving as many as 30 flake removals from one core, and by 1.7 Ma, they were also capable of making stereotypically symmetrical handaxes that required some mental template (Roche et al., 1999; Wynn, 2002). In addition, however hominids hunted, either by walking or running, they would have needed to track wounded prey in the absence of any sophisticated projectile technology to dispatch their prey instantly (see below). Thus, despite our lack of definitive evidence, the reasonable null hypothesis should be that early Homo had the cognitive skills necessary to track. Tracking must be as old as hunting, and it would have been more rather than less important during the Early Stone Age (ESA). We acknowledge that testing this hypothesis will be a challenge.

\section{Walking, running, and hunting without weapons}

Pickering and Bunn (2007) also suggest that ER was unnecessary for hunting in early Homo, yet they do not provide an adequate explanation for how early Homo hunted without projectile weapons. We agree that hominids were actively hunting by the time that $H$. erectus appeared (see Potts, 1988; Bunn, 2001; Dominguez-Rodrigo, 2002), but we challenge the idea that hunting without using ER would have been either effective or safe for hominids in the absence of lethal projectile weapons.

Several lines of evidence underlie our argument. First, we agree with Pickering and Bunn that early Homo lacked any serious weapons. Despite claims to the contrary (Clark, 1955; O'Brien, 1981), evidence that ESA tools such as Acheulian handaxes and spheroids could have been used as weapons is weak or equivocal (Shea, 2006b). Handaxes perform poorly as projectiles (Whittaker and McCall, 2001), and it is a myth that spheroids (putative bola stones) are found at ESA sites in groups of two or three (cf. Cole, 1963: 148). It is more plausible that ESA weapons included sharpened wooden spears, such as those recovered at Schöningen, Germany (ca. 400 ka), but we know that early Homo did not make stone- or bone-tipped spears, which are capable of inflicting serious damage from a distance (see below). More effective hunting technologies, such as the bow and arrow and the spear thrower (atlatl), were not invented until after the origin of $H$. sapiens (Shea, 2006a). Thus, the hunting strategies of recent huntergatherers such as the Hadza and the Bushmen, who hunt with bows and arrows, poison, and tipped spears, are not useful analogues for those of early Homo.

Second, in spite of the limitations of ethnographic and ethnohistoric evidence, it is clear that hunting without long-range, lethal projectile weapons poses serious challenges. According to Binford (1984) and Churchill (1993), all recent hunters, including the Hadza and the Bushmen, use projectile technologies such as the bow and arrow. ESA hunters might have used hand-cast spears, but spears are rarely used in ambush, approach, or encounter hunting. Rather, spears are used to dispatch prey that have been immobilized or incapacitated by traps, hunting dogs, or other such means. Spears are ineffective at long distances, and their use poses substantial dangers to a hunter. According to Churchill (1993), the distance from which throwing spears are cast at prey by recent hunters averages only $7.8 \pm 2.2 \mathrm{~m}(n=14)$. Moreover, these distances mostly represent kills of animals that had already been immobilized and include data only for tipped spears. Stone, bone, or metal points vastly increase the spear's effectiveness because their greater sharpness improves the weapon's ability to penetrate hair and skin. In addition, tipped spears mostly disable or kill prey by causing hemorrhaging of internal organs or by laming an animal. Thus, hand-thrown, untipped wooden spears have a considerably lower ability to disable or mortally wound a large animal.

Hunters use stone- and bone-tipped armatures to improve penetration and thus minimize the chances that their target can recover or retaliate. It is possible to safely kill small animals such as duikers at close range by stabbing or clubbing them, but getting within a few meters of any medium- to large-sized animal is unquestionably risky. One well-aimed kick or impact with the animal's horns could cause serious, potentially fatal injury. Although we have no data on injury rates for humans who try to kill large animals at short range with ESA technology, rodeo athletes, who regularly interact at close quarters with large mammals, frequently break their legs and arms (Berger and Trinkaus, 1995)-life-threatening injuries for early humans. Indeed, large, wounded mammals sometimes inflict lethal or crippling wounds on modern hunters equipped with rifles (Capstick, 1977). Because ESA hunters using untipped spears apparently managed to hunt large mammals (e.g., Bunn and Kroll, 1986; Potts, 1988), we can infer that that they were somehow able to get close enough to their prey to kill them safely.

Pickering and Bunn (2007) do not explain how ESA hominids could have hunted without ER and projectile weapons other than to provide an ethnographic account that demonstrates that hominids could have walked during pursuit hunts. But walking alone does not accord well with the physiological evidence. It may be possible in extreme heat to outwalk a small ungulate such as duiker, but the point of PH is to keep an animal above its trot-gallop transition speed for long enough to cause it to develop hyperthermia (and not, as Pickering and Bunn suggest, to tire it). Running is necessary because most mammals can dissipate heat adequately via panting when walking or trotting but not when galloping. Galloping mammals cannot pant (Bramble and Jenkins, 1993; Entin et al., 1999). In contrast, mammals can walk or trot incredibly long distances at speeds that are faster than optimal human walking speeds, even in hot conditions (Dill et al., 1933). It is thus doubtful that humans could regularly drive large mammals to hyperthermia by walking. In fact, if such a strategy were possible, then it would surely be more common (why run if one could walk?).

Pickering and Bunn (2007) also mistakenly imply that running is much more costly and difficult than walking. Take their example of a hunter walking a duiker to hyperthermia in three hours. Assuming an average human optimal speed of $1.3 \mathrm{~m} / \mathrm{s}$, the hunter walked about $14 \mathrm{~km}$. Because the cost of walking is 
$0.161 \mathrm{O}_{2} / \mathrm{kg} / \mathrm{km}$ (Margaria et al., 1963; Cavagna and Kaneko, 1977), the hunter spent approximately $700 \mathrm{Kcal}$ (assuming a body mass of $65 \mathrm{~kg}$ and a conversion rate of $4.8 \mathrm{kcal} / 1$ $\mathrm{O}_{2}$ ). In contrast, if the hunter had run, then the cost of locomotion increases by only about $30 \%$ regardless of speed (to 0.211 $\mathrm{O}_{2} / \mathrm{kg} / \mathrm{km}$ ), costing $910 \mathrm{Kcal}$ ! A three-hour walk or run to hunt a duiker does not yield a very impressive return. If it is assumed that $60 \%$ of the mass of the duiker (which averages $13 \mathrm{~kg}$ ) is edible and an average yield of uncooked duiker meat of $2000 \mathrm{Kcal} / \mathrm{kg}$ (based on caribou [USDA, 2006]), then the hunter's efforts probably yielded about 15,600 Kcal. Yet, by running not walking, a hunter is much more likely to be able to drive a large mammal such as a kudu or wildebeest to hyperthermia with almost the same effort, increasing the yield by orders of magnitude. A $200 \mathrm{~kg}$ ungulate yields $240,000 \mathrm{Kcal}$ ! And while a hunter would have needed to rest the day after a $\mathrm{PH}$, this would have been true regardless of whether the hunter ran or walked, and whether he brought home a $13 \mathrm{~kg}$ duiker or a $200 \mathrm{~kg}$ wildebeest.

Finally, we agree that PH is not practiced by the Hadza and only rarely by Bushmen and other foragers. But Pickering and Bunn are wrong to contend that $\mathrm{PH}$ is ineffective. Approximately $50 \%$ of the persistence hunts documented by Liebenberg (2006) were successful, leading to an approximately $70 \%$ higher yield of meat per day than hunting using a bow and arrow. Persistence hunting is now rare not because it is ineffective, but because hunters no longer need to rely on the strategy, which is obviously more time- and energy-consuming than other currently available methods. Thus, it makes little sense to extrapolate how early Homo would have hunted without specialized projectile weapons, hunting dogs, or the other technological aids used by recent foragers. That said, $\mathrm{PH}$ has been documented for the Kalahari Bushmen (Schapera, 1930; Marshall, 1958; Washburn, 1960; Shostak, 1981; Liebenberg, 1990, 2006), the Tarahumara of northern Mexico (Bennett and Zingg, 1935; Balke and Snow, 1965; Groom, 1971; Pennington, 1963), the Navajo and Paiutes of the American Southwest (Nabokov, 1987), and Australian Aborigines (McCarthy, 1957). The fact that recent hunters occasionally use $\mathrm{PH}$ in spite of the other methods available to them is a testament to the strategy's effectiveness and minimal risk. Also, according to Marshall Thomas (2006), the Bushmen have moved away from a significant dependence on hunted game since the 1960s. Thus, the frequency of PH documented by Liebenberg (2006) is not a good estimator of its frequency prior to the arrival of agriculturalists and pastoralists, let alone the invention of the bow and arrow.

\section{Scavenging}

Pickering and Bunn (2007) also take issue with the hypothesis that ER would have been useful for scavenging. Regardless of whether or how much early hominids scavenged, there are several weaknesses to their arguments. First, they assume hominids did not scavenge in open habitats. This assumption is based on Blumenschine's $(1986,1987)$ evidence that the density of hyenas is lower and scavengeable carcasses survive for longer periods in riparian versus savannah habitats. Endurance running requires us to reconsider hominid scavenging opportunities. With ER capabilities, hominids could have had a previously unrecognized advantage scavenging in open habitats during the day when other scavengers are prevented from running long distances because of thermoregulatory constraints (hyenas confine their running to dawn, dusk, and night). Scavenged meat is always an ephemeral resource, requiring speed. Diurnal hominids in open habitats might not only have been able to identify scavenging opportunities by seeing vultures in the distance, often many kilometers away, but they also would have had a competitive advantage over hyenas for getting to carcasses during the day, particularly in the dry season. To what extent hominids scavenged this way is debatable, but the ethnographic evidence provides anecdotal support for the strategy's potential. O'Connell et al. (1988: 357) reported that, when Hadza see a scavenging opportunity, often from sighting vultures in the distance, they "abandon other activities and move quickly to the spot, often at a run" (emphasis added).

Further, as Tappen (2001) pointed out, the Serengeti is not typical of all habitats in the early Pleistocene; scavengeable carcasses might have been more available in wetter, less seasonally arid habitats (e.g., the Parc National des Virunga), but they still would have been rare and rapidly consumed. In such contexts, ER would have helped hominids compete with other scavengers.

To become scavengers (or hunters), hominids entered the carnivore guild, which meant competing with other carnivores using a combination of strength, speed, stealth, and cooperation (Van Valkenburgh, 2001). Modern foragers are no exception: a high percentage of scavenging opportunities observed among Hadza and other hunter-gatherers are classified as "competition" or "power" scavenging in which the foragers drive off lions or hyenas from a kill using weapons (O'Connell et al., 1988; Potts, 1988; Bunn and Ezzo, 1993). Because early Homo was neither strong nor powerful, and apparently lacked projectile weapons, it is debatable whether they could have engaged in competition scavenging. In the ESA, the speed afforded by ER may have been an even more essential component of scavenging than is presently the case.

Finally, there is one more context in which selection for ER, in association with both scavenging and limited $\mathrm{PH}$, might have taken place. As proposed by Sinclair et al. (1986), early hominids might have followed migrating ungulates as the savannahs opened up at the end of the Pliocene. Proximity to large ungulate herds would have offered many scavenging opportunities for fresh carcasses, and opportunities for $\mathrm{PH}$ that relied on both walking and ER. In fact, one can hypothesize that, initially, selection for ER might have favored hunters who were better able to run down naturally "disadvantaged" ungulates with reduced stamina (e.g., the very young, or weakened adults).

\section{Conclusion}

We will never know for sure why and how ER capabilities evolved, but the modern ethnographic record is a limited, biased, and sometimes misleading source of evidence to test hypotheses about how ESA hominids hunted and scavenged. The challenge for paleoanthropologists is to explain the past 
in terms of testable hypotheses derived from actualistic studies and middle-range research without succumbing to the "tyranny of ethnography." We also recognize the difficulties of testing hypotheses about how, when, and why ER evolved. At this point, all we can say is that there are several lines of evidence cited above and elsewhere (Carrier, 1984; Bramble and Lieberman, 2004; Liebenberg, 2006) that ER capabilities would have improved the performance of hominids to hunt and/or scavenge using just an ESA technology. These capabilities may have enabled early Homo to occupy a new niche, that of a diurnal social carnivore. In fact, without projectiles, it is hard to imagine how early Homo in the ESA would have either scavenged or hunted safely and effectively unless they employed ER to some extent. That said, we are not proposing that $\mathrm{PH}$ was the exclusive method for hunting, that all scavenging was dependent on ER, or that $H$. erectus had all the ER capabilities of modern humans. Instead, all we can infer is that there is good evidence that $H$. erectus was capable to some extent of ER and that ER would have increased their fitness.

\section{References}

Balke, B., Snow, C., 1965. Anthropological and physiological observations on Tarahumara endurance runners. Am. J. Phys. Anthropol. 23, 293-301.

Bennett, W.C., Zingg, R.M., 1935. The Tarahumara: An Indian Tribe of Northern Mexico. University of Chicago Press, Chicago.

Berger, T.D., Trinkaus, E., 1995. Patterns of trauma among the Neandertals. J. Archaeol. Sci. 22, 841-852.

Binford, L., 1984. Bones of contention: A reply to Glynn Isaac. Am. Antiq. 49, $164-167$.

Blumenschine, R.J. 1986. Early Hominid Scavenging Opportunities: Implications of Carcass Availability in the Serengeti and Ngorongoro Ecosystems. British Archaeological Reports International Series 283, Oxford.

Blumenschine, R.J., 1987. Characteristics of an early hominid scavenging niche. Curr. Anthropol. 28, 383-407.

Bramble, D.M., Lieberman, D.E., 2004. Endurance running and the evolution of Homo. Nature 432, 345-352.

Bramble, D.M., Jenkins Jr., F.A.J., 1993. Mammalian locomotor-respiratory integration: implications for diaphragmatic and pulmonary design. Science $262,235-340$.

Bunn, H.T., 2001. Hunting, power scavenging, and butchering by Hadza foragers and by Plio-Pleistocene Homo. In: Stanford, C.B., Bunn, H.T. (Eds.), MeatEating and Human Evolution. Oxford University Press, Oxford, pp. 199-218.

Bunn, H.T., Ezzo, J.A., 1993. Hunting and scavenging by Plio-Pleistocene hominids: Nutritional constraints, archaeological patterns, and behavioural implications. J. Archaeol. Sci. 20, 365-398.

Bunn, H.T., Kroll, E.M., 1986. Systematic butchery by Plio-Pleistocene hominids at Olduvai Gorge, Tanzania. Curr. Anthropol. 27, 431-452.

Capstick, P.H., 1977. Death in the Long Grass. St. Martins Press, New York.

Carrier, D.R., 1984. The energetic paradox of human running and hominid evolution. Curr. Anthropol. 24, 483-495.

Cavagna, G.A., Kaneko, M., 1977. Mechanical work and efficiency in level walking and running. J. Physiol. 268, 467-481.

Churchill, S.E., 1993. Weapon technology, prey size selection and hunting methods in modern hunter-gatherers: implications for hunting in the Palaeolithic and Mesolithic. In: Peterkin, G.L., Bricker, H.M., Mellars, P.A. (Eds.), Hunting and Animal Exploitation in the Later Palaeolithic and Mesolithic of Eurasia. Archeological Papers of the American Anthropological Association 4, pp. 11-24.

Clark, J.D., 1955. The stone ball: its associations and use by prehistoric man in Africa. In: Balout, L. (Ed.), Congres Panafricain de Prehistoire, IIe session. Arts et Metiers Graphiques, Paris, pp. 403-407.

Cole, S., 1963. The Prehistory of East Africa. Mentor, New York.
Dill, D.B., Bock, A.V., Edwards, H.T., 1933. Mechanism for dissipating heat in man and dog. Am. J. Phyisol. 104, 36-43.

Dominguez-Rodrigo, M., 2002. Hunting and scavenging by early humans: The state of the debate. J. World Prehist. 16, 1-54.

Entin, P.L., Robertshaw, D., Rawson, R.E., 1999. Effect of locomotor respiratory coupling on respiratory evaporative heat loss in the sheep. J. Appl. Physiol. 87, 1887-1893.

Groom, D., 1971. Cardiovascular observations on Tarahumara Indian runners-the modern Spartans. Am. Heart J. 81, 304-314.

Liebenberg, L., 1990. The Art of Tracking: The Origin of Science. David Philip Publishers, Claremont, South Africa.

Liebenberg, L., 2006. Persistence hunting by modern hunter-gatherers. Curr. Anthropol. 47, 1017-1026.

Margaria, R., Cerretlli, P., Aghemo, P., Sassi, G., 1963. Energy cost of running. J. Appl. Physiol. 18, 367-370.

Marlowe, F.W., 2005. Hunter-gatherers and human evolution. Evol. Anthropol. $14,54-67$.

Marshall, J., 1958. Man as hunter. Nat. Hist. 72, 291-309. 376-395.

Marshall Thomas, E., 2006. The Old Way: A Story of the First People. Farrar, Straus Giroux, New York.

McCarthy, F.D., 1957. Australian Aborigines: Their Life and Culture. Colorgravure Publications, Melbourne.

Nabokov, P., 1987. Indian Running: Native American History and Tradition. Ancient City Press, Santa Fe.

O'Connell, J.F., Hawkes, K., Blurton-Jones, N.G., 1988. Hadza scavenging: implications for Plio-Pleistocene hominid subsistence. Curr. Anthropol. 29, 356-363.

O'Brien, E., 1981. The projectile capabilities of an Acheulian handaxe from Olorgesailie. Curr. Anthropol. 22, 76-79.

Pennington, C.W., 1963. The Tarahumara of Mexico: Their Environment and Material Culture. University of Utah Press, Salt Lake City.

Pickering, T.R., Bunn, H.T., 2007. The endurance running hypothesis and hunting and scavenging in savanna-woodlands. J. Hum. Evol. 53, 438-442.

Porter, J., Craven, B., Khan, R.M., Chang, S.J., Kang, I., Judkewicz, B., Volpe, J., Settles, G., Sobel, N., 2007. Mechanisms of scent tracking in humans. Nat. Neurosci. 10, 27-29.

Potts, R., 1988. Environmental hypotheses of human evolution. Yearb. Phys. Anthropol. 41, 93-136.

Roche, H., Delagnes, A., Brugal, J.-P., Feibel, C., Kibunjia, M., Mourre, V., Texier, P.-J., 1999. Early hominid stone tool production and technical skill 2.34 Myr ago in West Turkana, Kenya. Nature 399, 57-60.

Schapera, I., 1930. The Khoisan Peoples of South Africa: Bushmen and Hottentots. Routledge and Kegan Paul, London.

Shea, J.J., 2006a. The origins of lithic projectile point technology: evidence from Africa, the Levant, and Europe. J. Archaeol. Sci. 33, 823-846.

Shea, J.J., 2006b. What stone tools can (and can't) tell us about early hominin diets. In: Ungar, P. (Ed.), Evolution of the Human Diet: The Known, the Unknown, and the Unknowable. Oxford University Press, Oxford, pp. 321-351.

Shostak, M., 1981. Nisa: The Life and Words of a !Kung Woman. Harvard University Press, Cambridge.

Sinclair, A.R.E., Leakey, M.D., Norton-Griffiths, M., 1986. Migration and hominid bipedalism. Nature 324, 307-308.

Tappen, M., 2001. Deconstructing the Serengeti. In: Stanford, C.B., Bunn, H.T. (Eds.), Meat-Eating and Human Evolution. Oxford University Press, Oxford, pp. 13-32.

USDA, 2006. USDA National Nutrient Database for Standard Reference, Release 19. Nutrient Data Laboratory Home Page, http://www.ars.usda.gov/ba/bhnrc/ndl.

Van Valkenburgh, B., 2001. The dog-eat-dog world of carnivores: a review of past and present carnivore community dynamics. In: Stanford, C.B., Bunn, H.T. (Eds.), Meat-Eating and Human Evolution. Oxford University Press, Oxford, pp. 101-121.

Washburn, S.L., 1960. Tools and human evolution. Sci. Am. 203, 169-181.

Whittaker, J.C., McCall, G., 2001. Handaxe-hurling hominids: An unlikely story. Curr. Anthropol. 42, 566-572.

Wobst, M., 1978. The archaeo-ethnology of hunter-gatherers or the tyranny of the ethnographic record in archaeology. Am. Antiq. 43, 303-309.

Wynn, T., 2002. Archaeology and cognitive evolution. Behav. Brain Sci. 25, $389-402$. 